\title{
Cortical GABA Interneurons in Neurovascular Coupling: Relays for Subcortical Vasoactive Pathways
}

\author{
Bruno Cauli, ${ }^{1 *}$ Xin-Kang Tong, ${ }^{2 *}$ Armelle Rancillac, ${ }^{1}$ Nella Serluca, ${ }^{2}$ Bertrand Lambolez, ${ }^{1}$ Jean Rossier, ${ }^{1}$ \\ and Edith $\mathrm{Hamel}^{2}$ \\ ${ }^{1}$ Laboratoire de Neurobiologie et Diversité Cellulaire, Centre National de la Recherche Scientifique Unité Mixte de Recherche 7637, Ecole Supérieure de \\ Physique et de Chimie Industrielles de la ville de Paris, 75005 Paris, France, and ${ }^{2}$ Laboratory of Cerebrovascular Research, Montréal Neurological Institute, \\ McGill University, Montréal, Québec, Canada H3A 2B4
}

The role of interneurons in neurovascular coupling was investigated by patch-clamp recordings in acute rat cortical slices, followed by single-cell reverse transcriptase-multiplex PCR (RT-mPCR) and confocal observation of biocytin-filled neurons, laminin-stained microvessels, and immunodetection of their afferents by vasoactive subcortical cholinergic (ACh) and serotonergic (5-HT) pathways. The evoked firing of single interneurons in whole-cell recordings was sufficient to either dilate or constrict neighboring microvessels. Identification of vasomotor interneurons by single-cell RT-mPCR revealed expression of vasoactive intestinal peptide (VIP) or nitric oxide synthase (NOS) in interneurons inducing dilatation and somatostatin (SOM) in those eliciting contraction. Constrictions appeared spatially restricted, maximal at the level of neurite apposition, and were associated with contraction of surrounding smooth muscle cells, providing the first evidence for neural regulation of vascular sphincters. Direct perfusion of VIP and NO donor onto the slices dilated microvessels, whereas neuropeptide Y (NPY) and SOM induced vasoconstriction. RT-PCR analyses revealed expression of specific subtypes of neuropeptide receptors in smooth muscle cells from intracortical microvessels, compatible with the vasomotor responses they elicited. By triple and quadruple immunofluorescence, the identified vasomotor interneurons established contacts with local microvessels and received, albeit to a different extent depending on interneuron subtypes, somatic and dendritic afferents from ACh and 5-HT pathways. Our results demonstrate the ability of specific subsets of cortical GABA interneurons to transmute neuronal signals into vascular responses and further suggest that they could act as local integrators of neurovascular coupling for subcortical vasoactive pathways.

Key words: brain microcirculation; cerebral blood flow; neocortex; neuropeptide Y; nitric oxide; somatostatin; vasoactive intestinal peptide

\section{Introduction}

The tight coupling between local perfusion and neuronal activity is central to normal brain function. Many cellular components are involved in this neurophysiological response, which is at the basis of the signals used in functional neuroimaging (Logothetis et al., 2001; Lauritzen and Gold, 2003; Iadecola, 2004). In brain

\footnotetext{
Received July 27, 2004; revised Aug. 25, 2004; accepted Aug. 28, 2004.

This work was supported by Canadian Institute of Health Research Grant MOP-53334 (E.H.), a Blaise Pascal International Research Chair from the Region lle-de-France (E.H.), a Le Fonds de la Recherche en Santé de QuébecInstitut National de la Santé et de la Recherche Médicale exchange program (E.H. and B.C.), and a Centre National de la Recherche Scientifique grant (J.R.). We thank M. St.-Georges and R. Sampson (Montréal Neurological Institute, Montréal, Québec, Canada) for their contribution to the initial morphological studies and I. Ferezou, E. Hill, N. Gibelin, and A. Meunier (Laboratoire de Neurobiologie et Diversité Cellulaire, Paris, France) for their valuable comments and help in training E.H. in electrophysiological recordings (IF) and performing early (EHi) or some (NG, AM) single-cell RT-PCR analyses. We are grateful to Dr. B. K. Hartman (University of Minnesota, Minneapolis, MN) for his generous gift of the ChAT antibody. We particularly recognize the contribution of Dr. P. Séguéla (Montreal Neurological Institute, McGill University, Montréal, Québec, (anada) in designing the PCR primers for VIP and (CK receptors. We also thank L. Michel for her preparation of the final manuscript.

*B.C. and X.-K.T. contributed equally to this work.

Correspondence should be addressed to Dr. Edith Hamel, Laboratory of Cerebrovascular Research, Montreal Neurological Institute, 3801 University Street, Room 748, Montréal, Québec, Canada H3A 2B4. E-mail: edith.hamel@mcgill.ca.

D01:10.1523/JNEUROSCI.3065-04.2004

Copyright $\odot 2004$ Society for Neuroscience $\quad 0270-6474 / 04 / 248940-10 \$ 15.00 / 0$
}

areas such as the cerebral cortex where vascular and neural architectures are well matched, local blood vessel geometry, density, and the peculiar arrangement of specific flow control structures appear fundamental to the spatial and temporal requirements of neurovascular coupling (Harrison et al., 2002; Iadecola, 2002). Moreover, the innervation of cortical microvessels by several neurotransmitter systems suggests that microvascular responses to perivascularly released neurotransmitters are important in locally adapting flow to changes in neuronal activity (for review, see Hamel, 2004; Iadecola, 2004) (Chédotal et al., 1994b; Cohen et al., 1996; Krimer et al., 1998; Paspalas and Papadopoulos, 1998). Recently, somatosensory cortical hemodynamic responses have been shown to correlate with local field potentials, findings that imply that the vascular changes reflect the incoming neuronal inputs and local processing in a given area (Logothetis et al., 2001; Lauritzen and Gold, 2003; Iadecola, 2004).

In the cerebral cortex, such an integrating role has been attributed to local GABA interneurons (Kawaguchi and Kubota, 1997). Interestingly, these neurons also provide an exceptionally rich innervation to local microvessels, an observation that led to the suggestion that they could act as integrators of local vascular responses (Vaucher et al., 2000). Yet, multiple subpopulations of 
GABA interneurons have been identified in the cerebral cortex. They are highly diverse in morphology, connectivity, and firing patterns as well as in the substances they express (Cauli et al., 1997; Kawaguchi and Kubota, 1997), many of which being vasoactive. As well, apart from specific subsets of GABA interneurons identified as anatomical or functional targets for (basal forebrain) cholinergic (ACh) and/or brainstem raphe nucleus serotonergic (5-HT) neurons (Vaucher et al., 1997; Porter et al., 1999; Ferezou et al., 2002), two subcortical systems known to elicit changes in cortical perfusion after stimulation (for review, see Hamel, 2004) (Cohen et al., 1996; Iadecola, 2004), little is known about the input to cortical interneurons by both ACh and 5-HT afferent systems.

Here, we combined patch-clamp recordings in acute rat cortical slices with single-cell reverse transcription-multiplex PCR (RT-mPCR), followed by confocal observation of biocytin-filled neurons, laminin-stained blood vessels, and immunostained ACh [choline acetyltransferase (ChAT)] and 5-HT nerve fibers. We show that stimulation of single cortical interneurons, depending on subtype, can constrict or dilate cortical microvessels, that these vasomotor neurons establish contacts with reactive microvessels, and are targets for subcortical vasoactive ACh and 5-HT systems. Expression (RT-PCR) of receptors for neuropeptides contained within the vasomotor interneurons was determined in microvascular and astroglial cells, and the peptides ability to alter microvessel tone evaluated by their direct superfusion onto the slices. The findings demonstrate that specific subsets of cortical GABA interneurons can transmute incoming neuronal afferent signals into appropriate vascular responses and thus act as local integrators of neurovascular coupling.

\section{Materials and Methods}

Animals. Wistar rats [postnatal day 14 (P14) to P21; Charles River, L'Arbresle, France] were used for electrophysiological recording and immunofluorescence of injected neurons in rat acute brain slices. Sprague Dawley rats (190-250 gm; Charles River, Montréal, Québec, Canada) were used for immunostaining $(n=6)$ and lesion $(n=5)$ studies. All animals were housed in a temperature-controlled $\left(21-25^{\circ} \mathrm{C}\right)$ room under daylight conditions and were given water ad libitum. Experiments were approved by the animal ethics committees of the respective institutions.

Slice preparation and whole-cell recordings. Parasagittal vibratome-cut (Leica VT1000S Vibratome; Leica, Nussloch, Germany) acute slices (300 $\mu \mathrm{m}$ thick) of frontoparietal cortices were transferred to a chamber and perfused (1-2 $\mathrm{ml} / \mathrm{min}$ ) with oxygenated artificial CSF as described previously (Cauli et al., 1997). Patch pipettes (4-6 M $\Omega$ ) pulled from borosilicate glass were filled with $8 \mu \mathrm{l}$ of autoclaved RT-PCR internal solution (in mM): $144 \mathrm{~K}$ gluconate; $3 \mathrm{MgCl}_{2}$; 0.2 EGTA; 10 HEPES, pH 7.2 (285/ $295 \mathrm{mosm}$ ), and $2 \mathrm{mg} / \mathrm{ml}$ biocytin (Sigma, St. Louis, MO) for intracellular labeling. Neurons and blood vessels were located in the slice using infrared videomicroscopy with Dodt gradient contrast optics. Whole-cell recordings of the selected neurons were performed at room temperature $\left(20-25^{\circ} \mathrm{C}\right)$ using patch-clamp amplifier (Axopatch 200A; Axon Instruments, Foster City, CA). Digitized data of resting membrane potential and action potential discharges (using the I-clamp fast mode of the amplifier) were acquired and analyzed using pCLAMP 8 software (Axon Instruments) for electrophysiological characterization of neurons (Cauli et al., 2000).

Cytoplasm harvest, intracellular labeling, and reverse transcription. After recording, the content of the cell was aspirated in the recording pipette and expelled into a test tube, and RT was performed in a final volume of $10 \mu \mathrm{l}$ as described previously (Lambolez et al., 1992). Slices were then fixed by immersion in $4 \%$ paraformaldehyde (PFA; 6-18 hr; $4^{\circ} \mathrm{C}$ ) for additional immunofluorescence labeling (see below).

$R T$-mPCR. To preserve mRNAs for single-cell RT-PCR analysis, whole-cell recording did not exceed $30 \mathrm{~min}$. The RT-mPCR protocol was designed to detect simultaneously and qualitatively at the single-cell level the expression of GAD65, GAD67, vasoactive intestinal peptide (VIP), cholecystokinin (CCK), ChAT, neuronal nitric oxide synthase (NOS), neuropeptide $\mathrm{Y}$ (NPY), and somatostatin (SOM) mRNAs using two amplification steps (Cauli et al., 1997). The nNOS primers were (GenBank accession number NM_012611; from $5^{\prime}$ to $3^{\prime}$, position 1 being the first base of the initiation codon): AACTGGGAGGGGAGAGGATTC (sense, position 2816), GGGTGGGAGGCGAGATTCAT (antisense, position 3344), yielding a 548 bp PCR product. All PCR primers amplified a cDNA region spanning at least one intron. Ten microliters of each individual second step PCR reaction were then viewed on an ethidium bromide-stained $1.5 \%$ agarose gel run with $\Phi \mathrm{x} 174$ cut by HaeIII as molecular weight markers.

Vascular reactivity. Blood vessels remaining in plane from layer I to layer III and exhibiting a well-defined luminal diameter of 5-30 $\mu \mathrm{m}$ were selected for single interneuron stimulation. Single interneurons (layer I to III) in vicinity $(<40 \mu \mathrm{m})$ of the selected vessel were recorded in wholecell configuration, and images of the blood vessel were acquired every 15 sec using Axon Imaging Workbench 2.2 (Axon Instruments). Baseline of the blood vessel was determined for $5 \mathrm{~min}$, and the patched neuron was then stimulated for 30 or $120 \mathrm{sec}$ by current injection eliciting a firing frequency of at least $8 \mathrm{~Hz}$ and left at its resting potential for an additional $5 \mathrm{~min}$. The luminal diameters of blood vessels were measured off-line using ImageTool 3.0 (University of Texas Health Science Center, San Antonio, TX). Neurons that did not sustain the required firing frequency over the stimulation period and blood vessels with unstable baseline were discarded from the analysis. For superfusion of vasoactive substances, VIP, SOM-14, NPY, CCK-8 (Bachem, Merseyside, UK), and 2-(N,Ndiethylamino)-diazenolate-2-oxide diethylammonium (DEA NONOate/) (Alexis Biochemicals, San Diego, CA) were bath applied after a 5 min baseline, and images were acquired every $15 \mathrm{sec}$. Vasodilatory substances were tested on vessels preconstricted (5-10 $\mathrm{min}$ ) to $\sim 30 \%$ of their initial diameter with $100 \mathrm{~nm}$ of the thromboxane A2 agonist 9,11dideoxy-11a,9a-epoxymethanoprostaglandin $\mathrm{F}_{2} \alpha$ (U46619) (Sigma), which also remained in the superfusion solution while testing the dilatory compound.

Tissue preparation for immunostaining and antibodies. Rats were anesthetized (Somnotol, $0.1 \mathrm{ml} / 100$ gm body weight; MTC Pharmaceuticals, Cambridge, Ontario, Canada), their brains perfusion-fixed $[800 \mathrm{ml}$ of $4 \% \mathrm{PFA}$ in $0.1 \mathrm{M}$ sodium phosphate buffer (PB), $\mathrm{pH} 7.2-7.4$ ], and vibratome-cut coronal sections ( $50 \mu \mathrm{m}$ thick) of the frontoparietal cortex were obtained as described previously (Tong and Hamel, 2000). All immunostainings were performed on free-floating sections incubated overnight for primary antibodies and $2-3 \mathrm{hr}$ for secondary antibodies. The primary antibodies were: mouse anti-ChAT (1:250; generously given by Dr. B. K. Hartman, University of Minnesota, Minneapolis, MN) (Chédotal et al., 1994b), guinea pig anti-VIP (1:6000; Peninsula Laboratories, Belmont, CA), rabbit anti-5-HT (1:10,000; Diasorin, Stillwater, $\mathrm{MN}$ ), or in the case of colabeling with NPY, a goat anti-serotonin transporter (1:100; Santa Cruz Biotechnology, Santa Cruz, CA), rabbit antiNPY (1:1000; Chemicon, Temecula, CA), sheep anti-neuronal NOS (1: 1000; Chemicon), mouse anti-laminin (1:6000; Chemicon), and rat antiSOM (1:150; Chemicon).

Immunofluorescence. Recorded biocytin-filled neurons and the different GABA interneurons (VIP, NOS, NPY, and SOM), their ACh (detected by its synthesizing enzyme ChAT), or 5-HT innervations and association with local blood vessels (immunostained for laminin) were assessed by triple or quadruple immunofluorescence and confocal microscopy. Unless otherwise stated, sections were simultaneously incubated with all primary antibodies against the targeted peptides or enzymes and the respective reactions visualized with species-specific cyanine 2 (Cy2)-, Cy3-, and Cy5-conjugated affiniPure secondary antibodies (Jackson ImmunoResearch, West Grove, PA), or AlexaFluor 488 (1:1000) goat anti-rat or donkey anti-goat (1:400) conjugated IgGs (Molecular Probes, Eugene, OR). The same fluorophore (Cy3) was used to detect blood vessel walls (laminin) and ChAT or NPY neuronal elements because their respective staining was strictly confined to vascular and neuronal elements with no overlap. For biocytin-filled neurons, biocytin was detected in first position with Streptavidin Alexafluor 488 and then 
ChAT, laminin, and 5-HT immunostainings were performed and detected with Cy3 and Cy5 fluorophores, respectively.

Basal forebrain lesion. The basal forebrain origin of the ACh afferents was determined in rats $(n=5)$ with unilateral (left) quisqualic acid lesion of the substantia innominata (Tong and Hamel, 2000). After 7-10 d survival time, brain sections were obtained and processed for double immunofluorescence for confocal analysis (NPY/ChAT and SOM/ChAT) or for quantitative immunocytochemistry on semithin sections (VIP/ChAT). In the later case, the avidinbiotin method was used, VIP was detected in the first position with the SG kit (blue precipitate; Vector Laboratories, Burlingame, CA), and ChAT in second position with the $\mathrm{DAB}$ substrate kit without nickel intensification (brown precipitate; Vector Laboratories) after reincubation of the sections overnight with the anti-ChAT antibody. Immunostained sections were then flat-embedded in Araldite 502 (JBEM Services, Montréal, Québec, Canada), and semithin $(3 \mu \mathrm{m})$ sections were prepared for observation under light microscopy (Tong and Hamel, 2000; Vaucher et al., 2000).

Confocal microscopy. The association of recorded cells with local blood vessels and their ACh and/or 5-HT afferents was evaluated by confocal microscopy (Zeiss LSM 510; Zeiss, Jena, Germany) using simultaneous triplechannel detection with emission intensity of $488 \mathrm{~nm}$ (AlexaFluor/Cy2), $543 \mathrm{~nm}$ (Cy3), and $640 \mathrm{~nm}$ (Cy5). The neurons were scanned through their entire thickness, and their vascular associations and axo-somatic and axodendritic afferents examined in single plane sections, reconstruction of the entire stacks was used for figure representation only. The different subsets of GABA interneurons, their innervation by ACh or 5-HT nerve fibers, and association with local blood vessels were similarly analyzed in single plane sections. Sections were observed across layers I-III of the cerebral cortex, cells were randomly selected ( $n=90-237$ neurons depending of cell types), and corresponding images in each channel grabbed for additional analysis and counting using the computer-assisted software Zeiss LSM Image Browser and Adobe Photoshop 5 or 7 (Adobe Systems, San Jose, CA) for illustration purposes.

PCR of receptors in microvascular cells. To assess whether or not cortical microvessels could potentially respond to perivascularly released neuropeptides from the identified GABA interneurons, we assessed, by RT-PCR, the expression of receptors for these peptides. Expression of receptors for VIP, CCK, and SOM was determined in human cerebromicrovascular endothelial (EC), smooth muscle (SMC), and fetal astroglial (AST) cell cultures generated as described previously (Abounader et al., 1999). The following primer pairs were used (receptor: GenBank accession number, primers, and length of PCR product): VPAC1: NM_004624.2, TCTACGGTTCTGTGAAGACCG (sense, position 523) and ACACCATGGTGAATGTGCTG, (antisense, position 908), 405 bp; VPAC2: X95097, CCTGTTCCTGTCCTTCATCC (sense, position 679) and TTGGCCAGCCTCTTGTACTG (antisense, position 1151), 492 bp; PAC1: D17516, TGGTCATCCTTTGTCGCTTC (sense, position 759) and ATGATAGAGCCAACCACAGGG (antisense, position 1177), 439 bp; CCK-A: NM_000730.1, TGGTCCTCTTCTTCCTGTGC (sense, position 1109) and TGCTCTGCTCCTTCTCTTCC, (antisense, position 1514), 425 bp; CCK-B: BT006789.1, TGTCCGGACTACTCATGGTG (sense, position 542) and GCTCAGCAAGTGAATGAAGG (antisense, position 1117), 596 bp; somatostatin
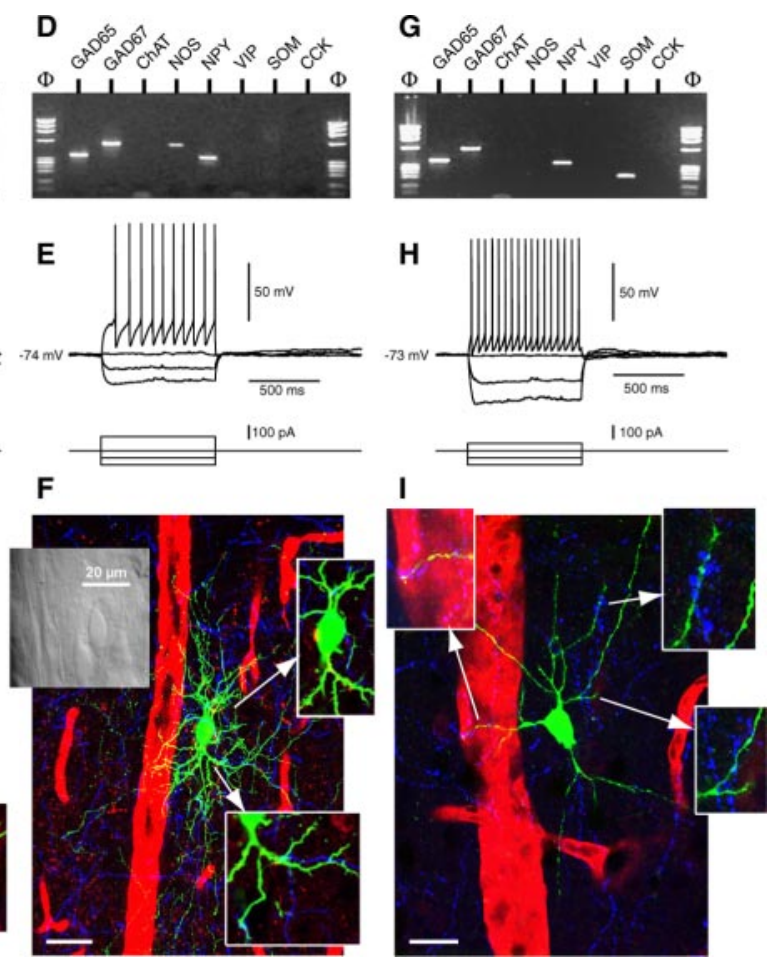

Figure 1. Molecular, electrophysiological, and morphological characterizations of perivascular neurons. $A$, Molecular analysis of a perivascular neuron expressing GAD65, GAD67, and VIP. B, Firing pattern of the same interneuron. Application of a $100 \mathrm{pA}$ depolarizing current pulse induced a discharge of action potentials with a marked frequency adaptation (top trace). Note the

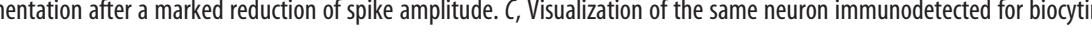
(blue) afferents. Top left, Inset, Morphology of the neuron as seen under infrared illumination. Insets, ACh (red) and 5-HT (blue) (he neuron soma and dendrites (green) in single-plane sections. D, Molecular analysis of another perivas cular neuron showing expression of GAD65, GAD67, NOS, and NPY.E, Firing pattern of the same interneuron. Application of a 100 $\mathrm{A}$ depolarizing current induced a discharge of action potentials with a slight increase in firing rate (top trace). Note the delay 0 列 adjacent blood vessel (left inset). Right insets, Appositions of 5-HT immunostained (blue) varicosities (blue) on the dendrites of the SOM neuron. Arrows in C, F, and / point to insets of the corresponding areas from each neuron. Scale bars: C, F, 30 $\mu \mathrm{m} ; \mathrm{l}, 20 \mu \mathrm{m}$.

receptor (SSTR)-1 and 2 (as described by Curtis et al., 2000) and SSTR-3-5 (as described by Dutour et al., 1998) generating PCR fragments of 375, 628, 654, 1035, and 298 for SSTR-1, SSTR-2, SSTR-3, SSTR-4 and SSTR-5, respectively. PCR was performed with 80 pmol of each primer pair using 1-4 $\mu \mathrm{l}$ of cDNA generated from DNase-treated RNAs, $250 \mu \mathrm{m}$ of each dNTPs, $3 \%$ of dimethylsulfoxide, $1.5-4.0 \mathrm{~mm} \mathrm{MgCl}_{2}$, $2.5 \mathrm{U}$ TaqDNA polymerase (Qiagen, Hilden, Germany) in a total volume of $50 \mu$ l. RNAs from EC, SMC, or AST not treated with RT were included in PCR reactions to control for possible contamination. PCR products were viewed on a $2 \%$ agarose gel stained with ethidium bromide, and identity was confirmed by sequencing (97-100\% for all receptors except CCK-A and CCK-B, which exhibited 92 and $90 \%$ identity, respectively, with published sequences).

Statistical analyses. To determine the statistical significance of the dilating and constricting responses, changes in diameter were compared using a paired $t$ test at the time before the onset of evoked firing or drug application where the mean diameter change is closest to $0 \%$ and at every $30 \mathrm{sec}$ interval after the stimulation. Quantification of neuronal density and perivascular $(<50 \mu \mathrm{m}$ from a vessel wall) distribution of specific subsets of GABA interneurons was achieved by direct counting in somatosensory cortex (superficial layers I-III) under a Leitz Aristoplan microscope (Leica, Montréal, Québec, Canada) equipped with epifluorescence in sections labeled for VIP(Cy2)-NPY, -SOM or -NOS(Cy3), or 

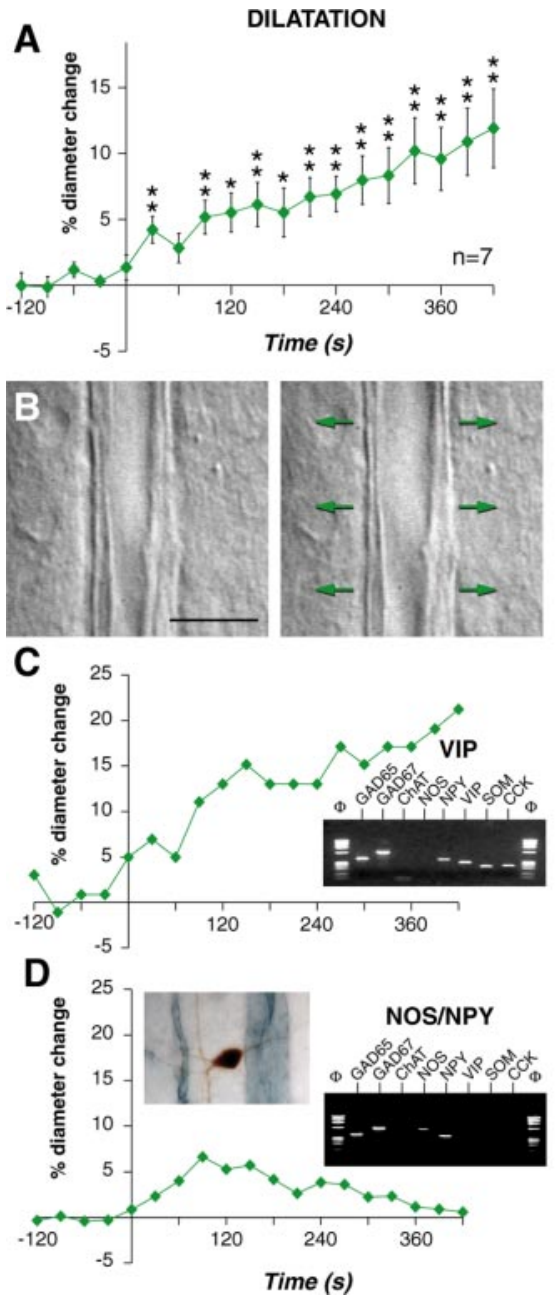
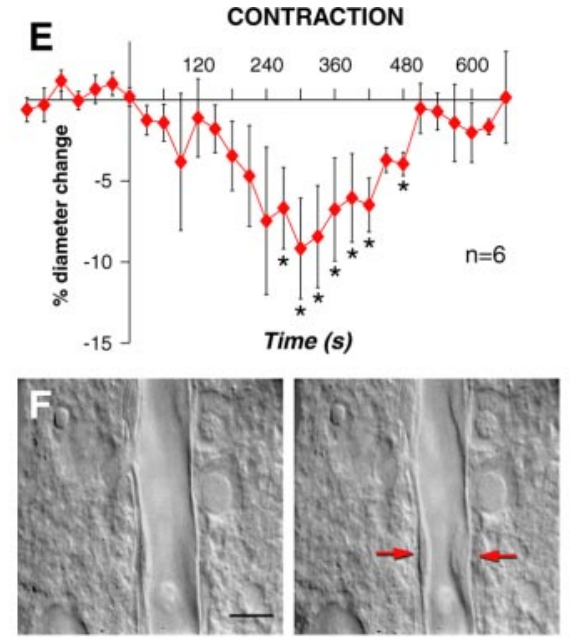

G

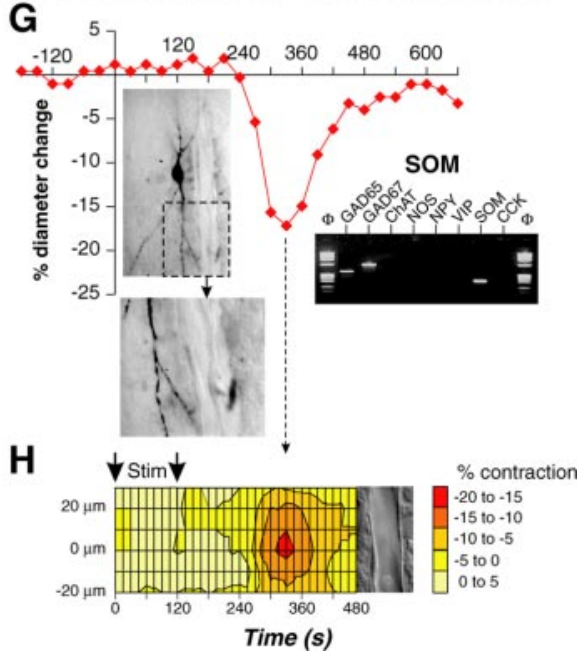

Figure 2. Single interneuron stimulation induces dilation or constriction of cortical blood vessels. $A, C, D, E, G$, Onsets of evoked firing start at a time of $0 \mathrm{sec}$. $A$, Mean values $\pm \mathrm{SEM}$ of dilating responses induced by evoked firing of different cortical interneurons $(n=7)$. Dilatation develops in phase with electrical stimulation. ${ }^{*} p<0.05$ and ${ }^{* *} p<0.01$ from prestimulation value. $B, F$, Images of blood vessels before (left) and after (right) electrical stimulation (120 sec) of the interneurons shown in $C$ and $G$, respectively. Scale bars, $10 \mu \mathrm{m}$. The arrows indicate regions of high vascular reactivity. $C$, Temporal response of the blood vessel shown in B. Inset, Molecular characterization of the stimulated interneuron showing expression of GAD65, GAD67, NPY, VIP, SOM, and CCK. D, Temporal response of a blood vessel evoked by electrical stimulation (30 sec) of another interneuron. Note the reversibility of the dilatation. Left inset, Morphology of the stimulated neuron (biocytin revealed with DAB; brown) showing a right horizontal dendritic arborization coursing toward the responsive blood vessel (immunodetected with laminin and the SG reagent; blue gray). Right inset, Molecular characterization of the stimulated interneuron showing expression of GAD65, GAD67, NOS, and NPY.E, Mean values \pm SEM of contracting responses evoked by electrical stimulation of different cortical interneurons ( $n=6$; ${ }^{*} p<0.05$ from prestimulation value). $G$, Temporal response of the blood vessel shown in $F$. Note the delay and the reversibility of the contraction. Left inset, Morphology of the stimulated neuron immunodetected for biocytin (DAB) showed a vertically oriented dendritic arborization. Bottom image shows a dendritic branch projecting toward the responsive blood vessel at the level of the highest vascular reactivity (red arrow in F; right panel). Right inset, Molecular characterization of the stimulated interneuron showing expression of GAD65, GAD67, and SOM. H, Spatiotemporal response of the blood vessel shown in Fdisclosing a delayed and spatially restricted contraction (hot spot; red). Amplitude of contraction is color coded (scale in percentage of contraction). The arrows indicate the duration of evoked firing. and SOM/ChAT) on both the control and lesion sides and comparison by Student's $t$ test. In all cases, a $p$ value of $<0.05$ was taken as significant.

\section{Results \\ GABA interneurons associate with microvessels and receive $\mathrm{ACh}$ and 5-HT afferents}

In a first attempt to identify the types of interneurons that associate with cortical microvessels, cells in layers I-III located within $50 \mu \mathrm{m}$ of the blood vessel walls (thereafter referred as perivascular) were located by infrared video microscopy, characterized by electrophysiological recordings, biocytin labeling, and single-cell RT-PCR. The injected neuron morphology, association with local blood vessels, and innervation by ACh or 5-HT afferent fibers were then studied by quadruple immunofluorescence and confocal microscopy. A total of 47 interneurons were analyzed, and 18 fulfilled all criteria: good electrophysiological recording, positive for the molecular GABA interneurons marker GAD65 and/or GAD67 and at least one other selected marker (i.e., VIP, NOS, NPY, and SOM) (Fig. $1 A, D, G$ ), and adequate intracellular biocytin labeling for additional morphological inspection. A majority of perivascular cells $(39 \% ; 7$ of 18) expressed VIP or NPY $(39 \% ; n=7)$, followed by cells expressing NOS (28\%; $n=5)$ or SOM $(28 \% ; n=5)$, some cells coexpressing more than one marker. In an independent series of experiments in rat brain sections immunostained for VIP/ SOM, VIP/NPY, VIP/NOS, or NPY/NOS with or without laminin immunodetection of blood vessel walls, perivascular neurons corresponded to VIP $(29.9 \%) \approx$ $\operatorname{SOM}(26.9 \%) \approx \operatorname{NPY}(24.2 \%) \approx$ and NOS $(18.9 \%)$ cells $(n=642$ vessels and 1288 neurons). Such distribution contrasted strikingly with their respective density in the same layers and fields of the somatosensory cortex, which was VIP $(46.1 \%)>$ $\operatorname{SOM}(30.4 \%)>\operatorname{NPY}(16.1 \%)>\mathrm{NOS}$ (7.4\%) $(n=1937$ neurons), indicative of a privileged redistribution of some interneurons in the vicinity of cortical microvessels.

When depolarized by current injection, NPY(Cy3)-NOS(Cy2) with or without laminin staining of vessel walls (Cy3). Proportions of interneurons (somata and proximal dendrites) contacted by ChAT and/or 5-HT afferents were determined from randomly scanned neurons ( $n=90-237$, in single plane sections by confocal microscopy) using the Zeiss LSM Image Browser software, and comparison was achieved by ANOVA and a Newman-Keuls post hoc comparison test. The effect of basal forebrain lesion on the ACh input to interneurons was evaluated either on semithin sections (2-3 sections per rat, for VIP/ ChAT) directly under the microscope (magnification of $400 \times$ and $1000 \times$ ) by two to three independent observers or after grabbing images in single-plane sections under the confocal microscope (for NPY/ChAT
VIP neurons either discharged an initial burst of action potentials followed by irregularly emitted action potential $(n=2)$ (Fig. $1 B)$ or exhibited regular spiking nonpyramidal (RSNP; $n=5$ ) firing pattern and were therefore identified as irregular spiking (IS; $n=$ 2) (Cauli et al., 1997) or RSNP-VIP $(n=5)$ neurons (Cauli et al., 2000). NPY-expressing interneurons sometimes coexpressed $\operatorname{SOM}(43 \% ; 3$ of 7$)$ (Fig. $1 G)$ and exhibited either RSNP $(n=3)$ or fast spiking (FS; $n=4$ ) (Fig. $1 \mathrm{H}$ ) firing pattern (Kawaguchi and Kubota, 1997). NOS neurons were mainly RSNP ( 4 of 5 ) cells, but 
one with a delay in the emission of the first action potential was identified as late spiking (LS) neuron (Kawaguchi and Kubota, 1997) and coexpressed NPY (Fig. 1E). SOM cells were typically characterized as RSNP (4 of 5) neurons. According to the morphological classification of cortical GABA interneurons (Kawaguchi and Kubota, 1997), perivascular VIP cells were all bipolar or bitufted (Fig. 1C), and NPY and NOS neurons were mainly multipolar or bitufted, with one NPY/NOS neuron showing the typical morphology of a neurogliaform cell (Fig. $1 F$ ). SOM neurons were large triangular, bitufted, or multipolar interneurons (Fig. 1I). Noteworthy, the recorded neurons not only contacted the neighboring penetrating microvessels identified by infrared videomicroscopy but their dendrites and/or axonal branches reached for several blood vessels within an area that extended $>100 \mu \mathrm{m}$ away from the cell soma (Fig. 1C, F, I). Confocal analysis revealed that perivascular neurons receive afferent inputs from both ACh and 5-HT punctate boutons that contacted their cell somata and proximal dendrites (Fig. 1C,F,I).

\section{Stimulation of single cortical interneurons triggers microvascular responses}

To assess the possibility that cortical interneurons are involved in neurovascular coupling, changes in diameter of microvessels evoked by electrical stimulation of single cortical interneurons were monitored in rat cortical acute slices (Sagher et al., 1993). Firing of action potentials at a frequency of at least $8 \mathrm{~Hz}$ was evoked in individual interneurons in layers I to III by injecting depolarizing current. Interneurons were thereafter electrophysiologically, molecularly, and morphologically characterized by single-cell RT-mPCR (Cauli et al., 1997). Vascular responses were observed in 13 of 149 stimulated interneurons (Fig. 2A,E) consisting of dilatation (mean maximal response, $11.9+3.0 \%$; $n=7$ ) or constriction (mean maximal response, $16.0 \pm 2.4 \%$; $n=6$ ). Interneurons inducing dilatation after stimulation were all classified as RSNP neurons (Cauli et al., 1997; Kawaguchi and Kubota, 1997), three were RSNP-VIP, two expressed NOS, and it was not possible to detect any mRNA in the two remaining neurons. Dilatations developed in phase with the evoked firing, and most of them (6 of 7) did not recover during the time of the recording (Fig. $2 A$ ). Figure $2 B$ shows an example of a microvessel dilating in response to the stimulation of a single GABA interneuron that expressed VIP, CCK, NPY, and SOM mRNAs (Fig. 2C, inset). The response (Fig. 2C) revealed a slowly developing dilatation reaching a maximum change in diameter of $21.2 \%$ at the end of the recording (supplemental material, available at www.jneurosci.org). Figure $2 \mathrm{D}$ shows the dilatory response of another microvessel starting at the beginning of the $30 \mathrm{sec}$ period of evoked firing, the diameter reached a maximal change of $6.6 \%$ and slowly returned close to its initial value. The molecular and morphological characterization of the stimulated GABA interneuron revealed the expression of NOS and NPY mRNAs and a horizontally oriented cell with a neurite projecting toward the responsive blood vessel (Fig. 2D, insets). panels, respectively).
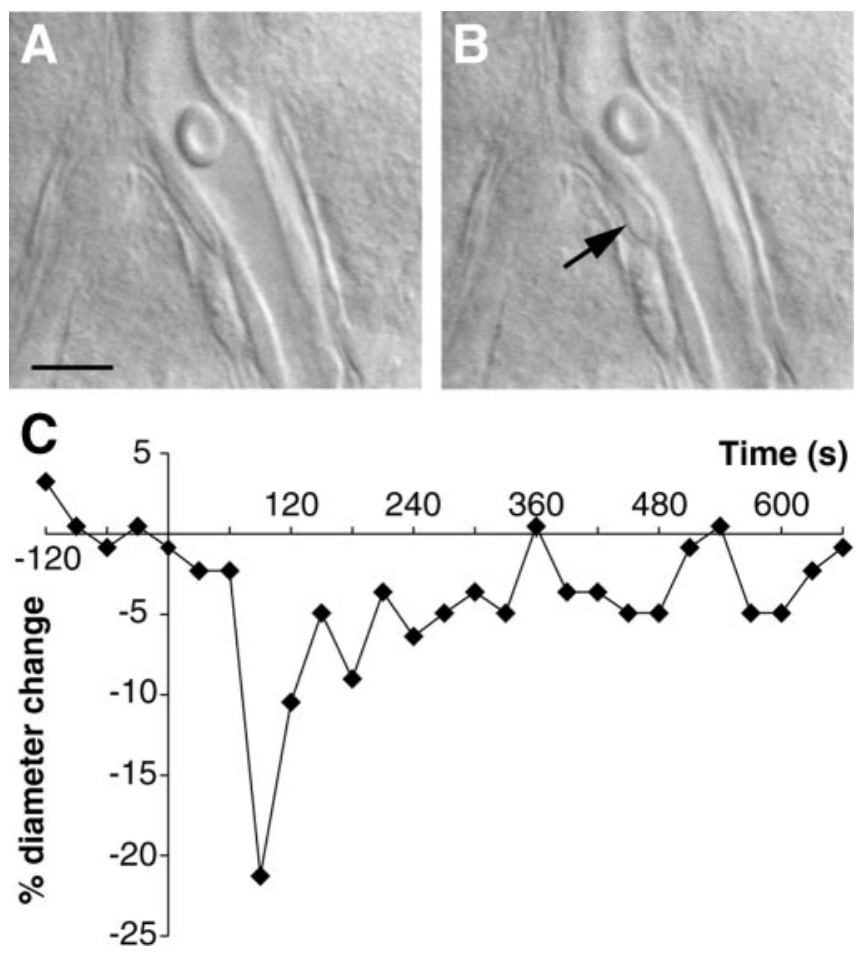

Figure 3. Contractile element in a cortical microvessel. Image of a small blood vessel showing the diameter and smooth muscle cell of the microvessel before $(A)$ and after $(B)$ the evoked firing $(120 \mathrm{sec})$ of a SOM interneuron identified by single-cell RT-PCR. The arrow in $B$ shows the contraction of a smooth muscle cell during the stimulation. Note the reduction of luminal diameter. C, Temporal response of the same blood vessel, onset of evoked firing started at a time of 0 sec and lasted $120 \mathrm{sec}$. Note the reversibility of the contraction. Scale bars, $10 \mu \mathrm{m}$.

In contrast to dilatations, some but not all constrictions were delayed with respect to evoked firing and were reversible (Fig. $2 E)$. Figure $2 F$ shows the vasoconstriction of a microvessel induced by the evoked firing of a nearby interneuron with a maximal response occurring $330 \mathrm{sec}$ after the beginning of the $120 \mathrm{sec}$
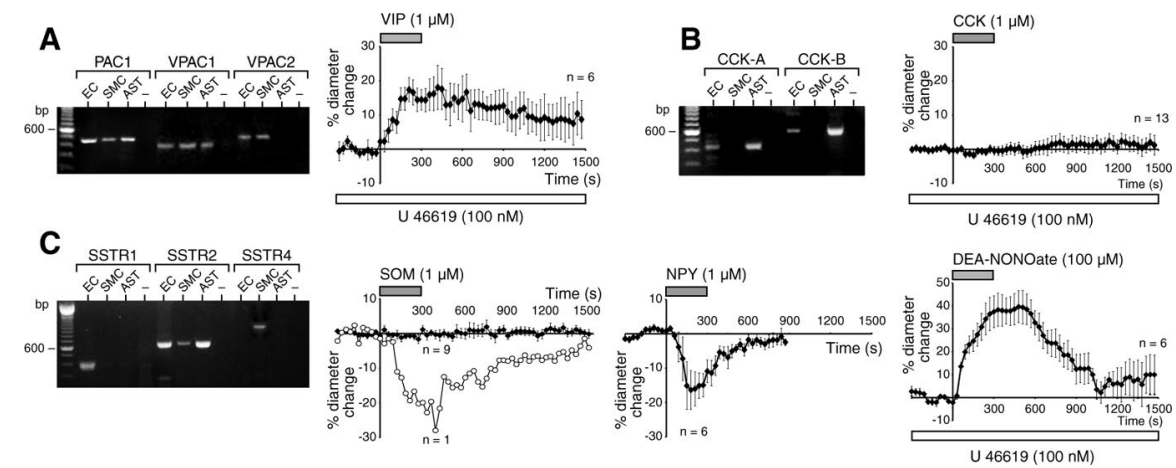

Figure 4. Molecular expression and vasomotor effects of microvascular receptors. Gel electrophoresis of PCR products for VIP $(A), C C K(B)$, and SOM ( $C$ receptor subtypes expressed in cultures of EC, SMC, and AST. Only products expressed in $50 \%$ or more of the cell cultures are illustrated. EC expressed all subtypes of VIP and CCK receptors and only SSTR1 and SSTR2. SMC were found to express all VIP receptor subtypes, no CCK receptors, and SSTR2 and SSTR4 receptors. In contrast, AST showed expression of PAC1, VPAC1, CCK-A, and CCK-B receptors and SSTR2 receptor subtypes. Samples without reverse transcriptase (-) were included to control for possible contamination. Vascular responses (mean \pm SEM) were evoked in cortical slices by bath application of different substances known to colocalize in different subsets of GABA interneurons. After preconstriction with U46619, VIP induced a dilatation in 6 of 10 microvessels ( $A$, right panel), whereas CCK failed to elicit any vasomotor response ( $B$, right panel; $n=13$ ). At baseline, most microvessels tested ( 9 of 10) were unresponsive to bath application of SOM ( $C$, second panel) except for one, which constricted in phase with the peptide application (open circles). A majority ( 6 of 7 ) of vessels reversibly constricted after NPY application, whereas the NO donor DEA NONOate strongly and reversibly dilated microvessels $(n=6$ of $14 ; C$, third and forth 
A
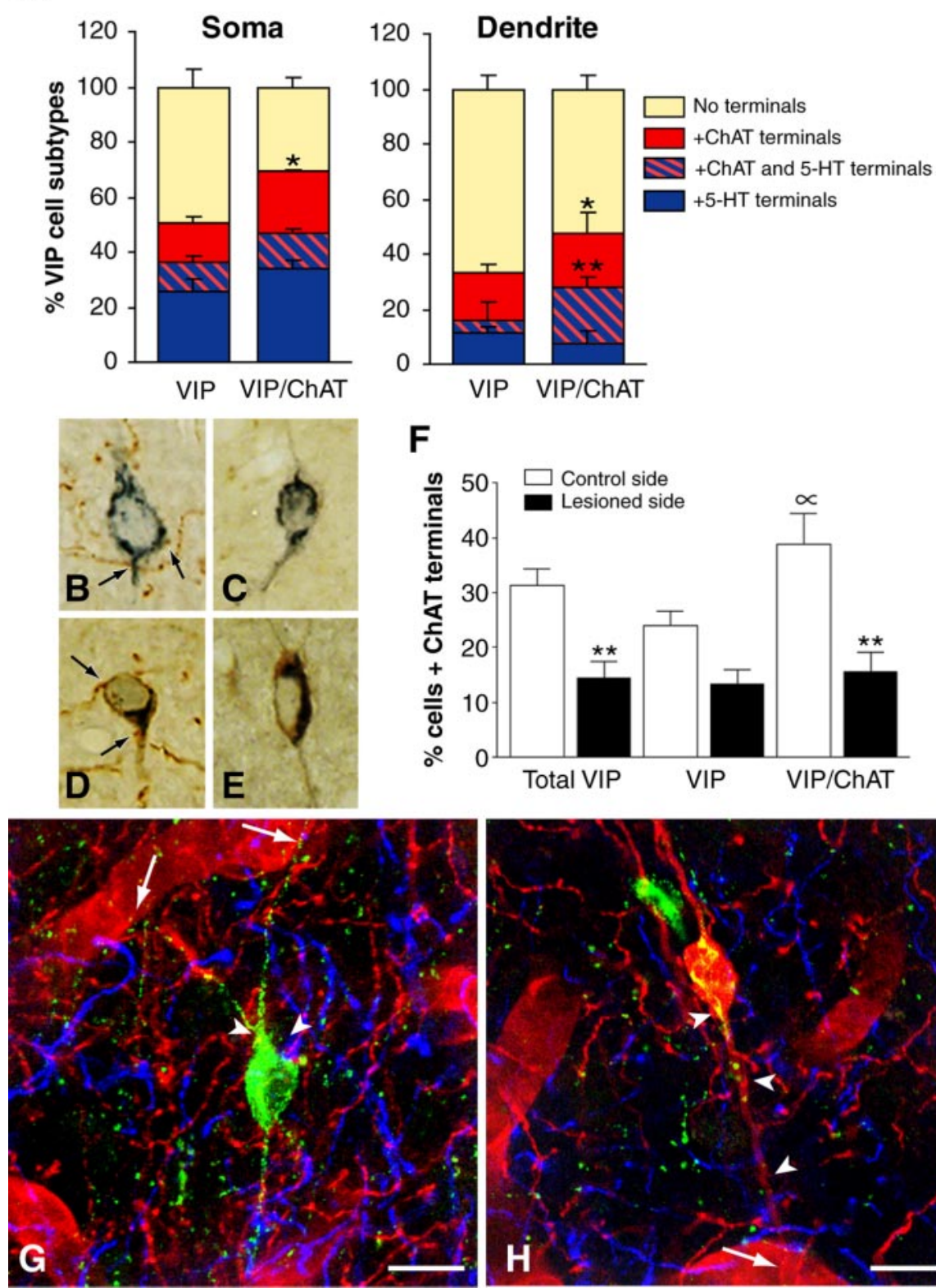

$\mathbf{F}$
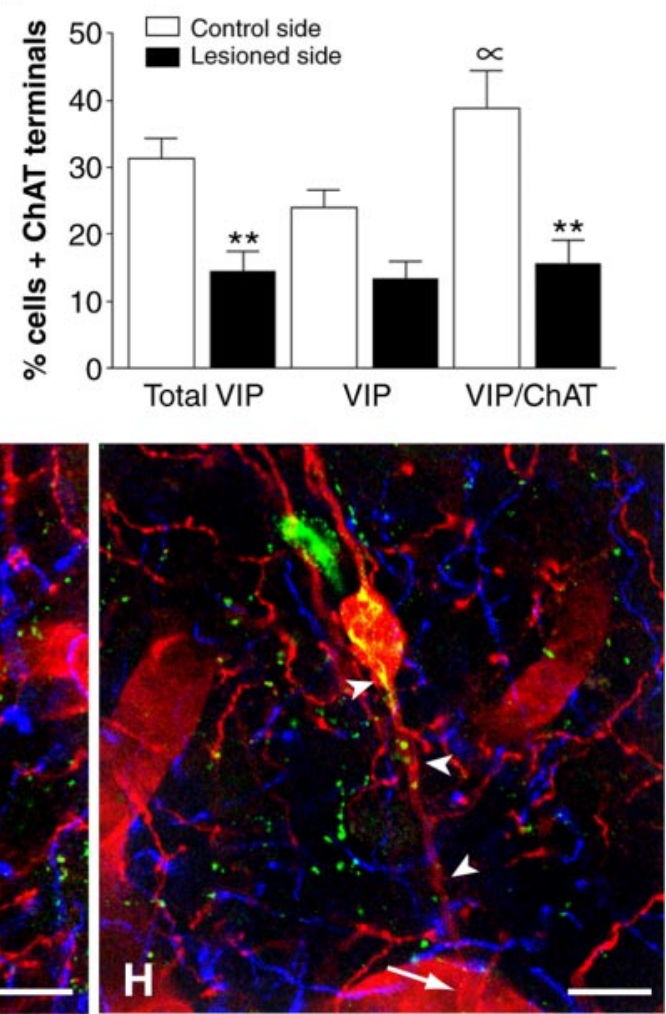

Figure 5. Identification of subsets of VIP interneurons and their ACh and 5-HT afferents. $A$, In triple-labeled sections for VIP, ChAT, and 5-HT, comparable proportions of soma $(\sim 40 \%)$ and dendrites $(\sim 20 \%)$ from VIP and VIP/ChAT neurons received 5-HT afferents (blue box). In contrast, a larger proportion of VIP/ChAT than VIP neurons was contacted by ACh afferents (red box) on both cell soma $(n=216 ; p<0.05)$ and dendrites $(n=186 ; p<0.05)$, and a larger proportion of VIP/ChAT dendrites also received both types of afferents $\left({ }^{* *} p<0.01\right.$; hatched red and blue box) compared with VIP dendrites. $B-F$, Effect of unilateral basal forebrain lesion on the ACh afferents to VIP interneurons as evaluated in semithin sections labeled for VIP (SG kit; blue) and ChAT (DAB; brown). Quantitative analysis of VIP and VIP/ChAT neurons on the control ( $B, D ; n=476$ cells) and lesioned ( $C, E ; n=$ 496 cells) sides, respectively, showed a significant loss of ACh input after lesion of substantia innominata ( $F$ ). Approximately $50 \%$ of the ACh innervation to the total VIP cell population $\left({ }^{* *} p<0.01\right)$ originated in the basal forebrain, with VIP/ChAT cells being significantly denervated $\left(60 \% ;{ }^{* *} p<0.01\right)$ but not the VIP $(44 \%$; NS) cells. Also, the analysis on the control side confirmed that VIP/ChAT cells received more ACh afferents than VIP cells $(\propto ; p<0.05)$. G, Quadruple immunofluorescence of a perivascular VIP neuron (green; Cy2) contacting a neighboring blood vessel (arrows; laminin-immunodetected with Cy3, red) and receiving both $\mathrm{ACh}$ (ChAT and Cy3; red) and 5-HT (5-HT and Cy5; blue) afferent terminals on its cell body or proximal dendrites (arrowheads). $H$, Quadruple immunofluorescence as in G but showing a VIP/ChAT interneuron (red/yellow) in contact with a blood vessel (arrow) and receiving dual $\mathrm{ACh}$ (red) and 5-HT (blue) innervations (arrowheads). Scale bars, $10 \mu \mathrm{m}$.

stimulus (supplemental material, available at www.jneurosci.org). The reduction in diameter reached a maximum of $-17.2 \%$ and returned almost to baseline (Fig. $2 G$ ). The stimulated GABA interneuron expressed SOM mRNA, exhibited ver- tically oriented bitufted morphology, and contacted theblood vessel wall near the site of the maximal contractile response (Fig. $2 G$, insets). The analysis of diameter change along the blood vessel revealed that the amplitude of the constriction was spatially restricted and was maximal at the level of the neuritic apposition (Fig. $2 \mathrm{H}$ ). In two of the six constrictions, reduction of luminal diameter was spatially limited by a clear contraction of an adjoining smooth muscle cell (Fig. $3 A, B$ ), as shown here after the evoked firing of an SOM expressing interneuron, which maximallyinduced constriction $(21.3 \%)$ occurred 90 sec after the onset of the $120 \mathrm{sec}$ stimulus and returned almost to baseline (Fig. 3C) (supplemental material, available at www.jneurosci.org). Three of six interneurons that induced constriction could be identified according to their firing properties and/or to their molecular content as RSNP-SOM cells (Cauli et al., 2000).

Expression and function of microcerebrovascular receptors for VIP, CCK, NPY, and SOM

To assess whether the release of neuropeptides expressed by the identified vasomotor neurons could be functionally relevant, we first studied VIP, CCK, and SOM receptor expression in different cellular compartments of resistance microvessels, as previously described for microvascular NPY Y1 receptors (Abounader et al., 1999). As illustrated in Figure $4(A-C$, left panels), microvascular endothelial cells expressed all subtypes of VIP and CCK receptors, but only the SSTR 1 and SSTR2 subtypes of SOM receptors were consistently ( $>50 \%$ of the preparations) expressed in these cells. In contrast, microvascular smooth muscle cells expressed all VIP receptors but none of the CCK receptors and only the SSTR2 and SSTR4 receptor subtypes. Yet, astrocytes, which are important in the glutamate-mediated neurovascular coupling (Zonta et al., 2003), expressed VIP (PAC1 and VPAC1), CCK-A, CCK-B, and SSTR2 receptors. None of the cell preparations consistently expressed SSTR3 and SSTR5 mRNAs. The ability of vasoactive substances expressed by perivascular interneurons to affect the tone of intracortical microvessels was then tested by their direct superfusion onto the slices. Perfusion of VIP and the NO donor DEA-NONOate, respectively, induced potent dilatations in $60 \%(n=10)$ and $43 \%$ $(n=14)$ of vessels preconstricted with the thromboxane A2 agonist U46619 (Fig. 4A,C, right panels). Maximal dilatations evoked by DEA NONOate were stronger $(39.7 \pm 7.0 \%)$ and more readily reversible than those elicited by VIP $(18 \pm 6.4 \%$; $p<$ 
0.05). In contrast, CCK was without effect on cortical vessels (Fig. $4 B$, right panel). In most microvessels (6 of 7), NPY induced reversible contractions $(16.0 \pm 4.9 \%)$, whereas most vessels ( 9 of 10 ) were unresponsive to SOM because only one reversibly contracted up to $28 \%$ of its basal tone after SOM perfusion (Fig. 4C, second and third panels).

\section{Innervation of different subsets of GABA interneurons by $\mathrm{ACh}$ and 5-HT terminals}

To assess whether GABA interneurons could serve as relay neurons for subcortical vasoactive systems in translating neuronal incoming signals into an adapted vascular response, we investigated their input from the basal forebrain ACh (immunostained for ChAT) and brainstem 5-HT afferents and their association with local microvessels by triple and quadruple immunofluorescence and confocal microscopy.

\section{VIP neurons}

VIP neurons were mainly bipolarbitufted neurons (Fig. 5G,H). In VIP, ChAT, and 5-HT triple-labeled sections ( $n=230$ cells from 3 rats), $40.1 \pm 2.7 \%$ of VIP neurons coexpress ChAT in line with previous reports (Chédotal et al., 1994a; Bayraktar et al., 1997). Although there was no difference between VIP and VIP/ChAT cell bodies or dendrites in their innervation by 5 -HT afferents, a significantly greater proportion of VIP/ChAT than VIP cells was contacted by ACh varicosities on both their somata (35.5 vs $24.5 \%$; $p<$ 0.05 ) and dendrites ( 39.8 vs $22.1 \% ; p<$ 0.05 ) (Fig. 5A). Approximately $10 \%$ of VIP and VIP/ChAT cell bodies $(n=216)$ received both ACh and 5-HT punctate boutons (Fig. $5 A$ ), with a higher proportion of VIP/ChAT than VIP dendrites being dually innervated (20 vs $4.67 \%$; $p<0.01$ ) (Fig. 5A). Approximately half of their ACh innervation disappeared after substantia innominata lesion, the denervation being more severe for VIP/ChAT $(60.0 \%$; $p<0.01)$ than for VIP (44.1\%; NS) cells (Fig. 5B-F). In sections labeled for VIP, ChAT, 5-HT, and laminin, 38.2 and $50.0 \%$ of VIP and VIP/ ChAT neurons $(n=121)$, respectively, contacted blood vessels in single plane section, some receiving both ACh and 5-HT axonal varicosities on their cell bodies and/or dendrites (Fig. 5G,H).

\section{NOS, NPY, and SOM}

NOS neurons corresponded mainly to multipolar, bitufted, and, less frequently, neurogliaform NPY cells, and they represented $69.1 \%(n=103)$ of the large NPY neurons. A larger proportion of NOS cells received somatic basal forebrain (Vaucher et al., 1997) ACh compared with brainstem 5 -HT afferents (69.0 vs $40.9 \%$; $p<0.05$ ) (Fig. $6 A$ ), with $30-35 \%$ of their somata or dendrites receiving both types of afferents (Fig. $6 A, B$ ). In sections immunostained for NOS, ChAT, 5-HT, and laminin or NOS and lami-

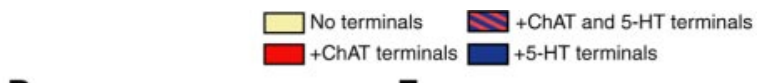

D

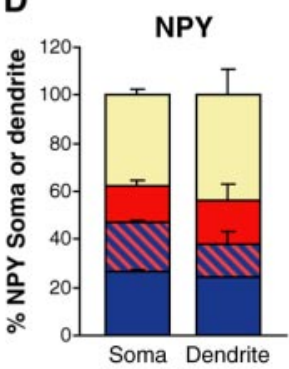

$\mathbf{F}$
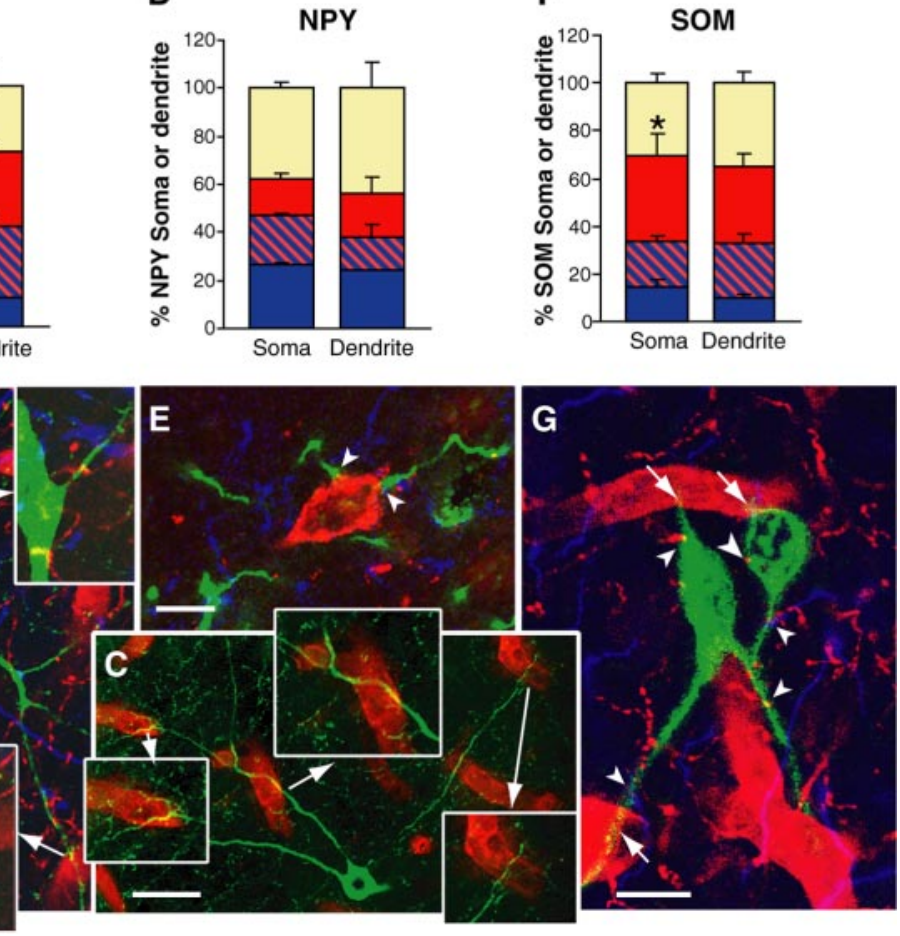

Figure 6. NOS, NPY, and SOM interneurons and their ACh (red box), 5-HT (blue box), and dual ChAT and 5-HT (hatched red and blue box) afferent inputs. $A$, Quantitative analysis of these innervations in NOS neurons ( $n=90$ somata and 85 dendrites) showed that a larger proportion of cell bodies was contacted by ACh varicosities compared with 5 -HT afferents ( ${ }^{*} p<0.05$ ). Note also that 5-HT, and laminin) showing a NOS interneuron (green) projecting to a surrounding blood vessel (bottom inset) and receiving both ACh (red) and 5-HT (blue) afferents in single-plane sections. Insets, ACh and 5-HT contacts are abundant on both cell soma and ( single NOS neuron with nearby and remotely located microvessels (insets). D, Quantitative analysis of ACh and 5-HT afferents to 作 contad by both types of varicosities. $F$, Quantitative analysis of AChand 5 -HTinnervations of SOM neurons ( $n=156$ somata and 112 dendrites) showed that a larger proportion of these cells $\left(\sim 60 \%\right.$; $\left.{ }^{*} p<0.05\right)$ received ACh terminals on their cell soma compared with 5-HT varicosities, with $\sim 20 \%$ of the cells receiving both types of afferents. G, Two perivascular SOM neurons (Cy2; green) contacting local blood vessels (arrows, laminin and Cy3; red) and receiving both ACh (ChAT and Cy3; red) and 5-HT (5-HT and (y5; blue) varicosities (arrowheads). Scale bars: $E, G, 10 \mu \mathrm{m} ; B, 20 \mu \mathrm{m} ; C, 30 \mu \mathrm{m}$.

$\operatorname{nin}(n=52), \sim 60 \%$ of NOS cells contacted local blood vessels either with their proximal or distal neurites in single-plane section, and many were dually innervated by ACh and 5-HT boutons (Fig. 6B). Their neuronal processes extended long distances and contacted a broad array of microvessels (Fig. $6 \mathrm{C}$ ). In contrast, only $\sim 32 \%$ of the small NPY neurons that did not colocalize NOS received ACh varicosities on their cell soma or dendrites (Fig. 6D), approximately half $(53.1 \%)$ of these originating in the basal forebrain. A slightly higher $(\sim 43 \%)$ proportion of these small NPY neurons were contacted by 5-HT boutons (Fig. 6E), with $\sim 17 \%$ being innervated by both $5-\mathrm{HT}$ and ACh varicosities (Fig. 6D). Small NPY neurons occasionally contacted local microvessels, but having few immunostained neurites, their frequency of vascular association was not determined. SOM neurons, akin to NOS cells, exhibited different morphologies, being either large triangular, bitufted, or multipolar cells, some having a horizontal orientation. Approximately half of their somata (57.4\%) and dendrites (48.7\%) (Fig. 6F) were innervated by ACh boutons that originated in part from the basal forebrain $(45 \%)$. Compared with their ACh input, smaller proportions of SOM 


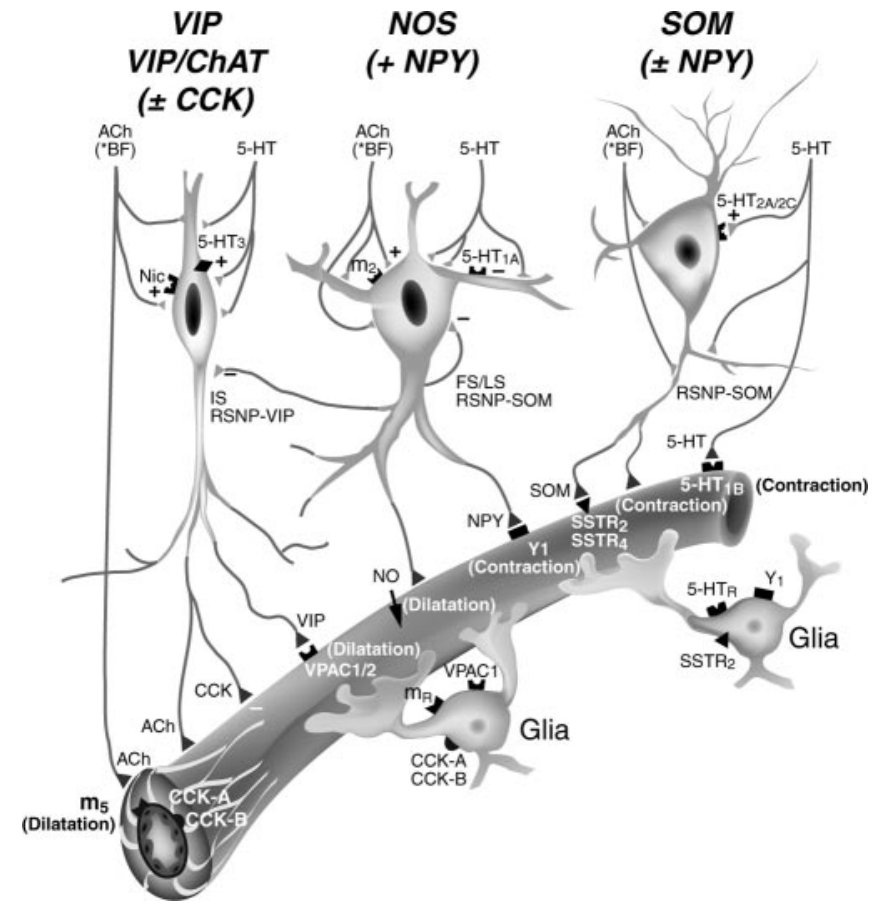

Figure 7. Schematic representation of the suggested role of cortical interneurons in neurovascular coupling and as possible relay neurons for vasoactive basal forebrain (BF) ACh and brainstem 5-HT systems. Their direct vasomotor effects are thought to be mediated by $\mathrm{m}_{5}$ muscarinic ACh receptor (dilatation) or $5-\mathrm{HT}_{1 \mathrm{~B}}$ receptor (constriction). However, the ability of these systems to target cortical GABA interneurons projecting to local microvessels that are endowed with subtype-specific receptors for vasoactive neuropeptides (VIP, NPY, or SOM) c0localized with GABA strongly support a role of cortical interneurons in modulating microvascular tone. A role for perivascular astrocytes cannot be excluded because they are neuropeptide receptive and are known to release vasodilatory mediators. Note that there is no receptor for CCK on smooth muscle cells and that this peptide failed to induce any vasomotor response. Also, cortical interneurons could serve as local relays in neurovascular coupling for other vasoactive afferent pathways (e.g., glutamate) (see Discussion).

neurons received somatic $(32.6 \% ; p<0.05)$ and dendritic (29.7\%; NS) 5 -HT afferents, with $\sim 19 \%$ being dually innervated (Fig. $6 F)$. Thirty percent of SOM neurons $(n=88)$ associated with blood vessels in single-plane sections, and approximately twice as many perivascular SOM neurons were contacted by ACh compared with 5-HT varicosities (Fig. 6G).

\section{Discussion}

Our results show that increased activity of single cortical interneurons results in precise vasomotor responses in neighboring microvessels, that these neurally induced vasomotor responses can be mimicked by perivascular application of vasoactive neuropeptides acting directly on microvascular receptors, and, finally, that these vasoactive interneurons are distinct targets for subcortical vasoactive pathways. These findings underscore the importance of neurovascular interactions in the hemodynamic changes that accompany enhanced cortical activity and that are at the basis of the signals used in functional neuroimaging.

\section{Interneuron activation alters microvascular tone}

The finding that the likelihood that VIP, NPY, SOM, or NOS neurons associate with cortical microvessels varies little [from $\sim 19 \%$ (NOS) to $30 \%$ (VIP); 1.6-fold], despite remarkable differences in their respective density within the somatosensory cortex: $\mathrm{VIP}>\mathrm{SOM}>\mathrm{NPY}>\mathrm{NOS}$ (6.3-fold between VIP and NOS) (Kubota et al., 1994; Estrada and DeFelipe, 1998; our study), provided the first indication of a cell type redistribution near cortical microvessels. This was particularly striking for NOS neurons emphasizing not only their perivascular localization (Estrada and DeFelipe, 1998) but their permissive role in functional hyperemia (Lindauer et al., 1999; Iadecola, 2004). This finding also agrees with previous reports of intimate associations between VIP, NPY, or NOS axonal varicosities or dendrites and cortical microvessels (Eckenstein and Baughman, 1984; Iadecola et al., 1993; Chédotal et al., 1994b; Abounader and Hamel, 1997).

A most extraordinary finding from our study was the demonstration that direct activation of a single interneuron is sufficient to either increase or decrease the diameter of a neighboring microvessel. Although the proportion of responding vessels was low, possibly caused by selection of a vessel not contacted by the stimulated neuron or of a nonresponsive area along the vessel wall, this finding clearly indicated that neuronal activation can directly alter microvascular tone. Both dilatation and constriction were observed. Surprising at first, these findings actually corroborate extremely well functional activation studies that showed both decreases and increases in perfusion signals accompanying neuronal activation under various physiological or pharmacological parameters (Woolsey et al., 1996; for review, see Raichle, 1998). Together, these observations unequivocally support that the increases in flow are associated with concomitant flow decreases in neighboring areas to redistribute blood where needed, agreeable to increased perfusion in discrete activated neuronal networks occurring "over a backdrop of stable perfusion to the entire brain" (Harder et al., 2002).

By single-cell RT-PCR, we identified at least two types of vasodilatory cells: VIP (Fig. 2C) and NOS (Fig. 2D) interneurons. All dilatations develop slowly and all but one did not reverse during the recording period. This failure of dilated blood vessels in brain slices to regain their initial diameter has been reported before and associated with lack of luminal flow or constricting tone (Sagher et al., 1993; Zonta et al., 2003) and to a high basal NOS activity (Fergus et al., 1996; Zonta et al., 2003). Note that the only reversible dilatation was induced by stimulation of a NOS neuron coexpressing NPY (Fig. 2D). This highlights the opposite roles of NO and NPY, respectively, potent dilator and constrictor, and the interpretation of their extensive colocalization (Kubota et al., 1994) as a mean to spatially limit the vasodilatory effect of the highly diffusible gas NO (Abounader and Hamel, 1997; Estrada and DeFelipe, 1998). In contrast to dilatations, constrictions were reversible. Remarkably, the decrease in luminal diameter was restricted along the vessel wall, with the most intense contraction occurring at the site of apposition between neuronal processes and the blood vessel (Fig. 2G,H). What is more, in some vessels, the contraction was confined to a bordering smooth muscle cell that spatially delineated the extent of the vascular response (Fig. 3). Together, these findings provide the first functional demonstration for neuronal modulation of anatomically identified vascular sphincters in microvessels and particularly so in arterioles that penetrate deep into the cortical parenchyma and suggested to regulate local blood flow (Nakai et al., 1989; Harrison et al., 2002).

\section{Vasoactive mediators}

The nature or source of the substances that mediate the interneuron-driven vascular responses cannot be ascertained from our study. Notwithstanding, the possibility that these responses are attributable to direct action of the peptides on microvessels was substantiated here by molecular and functional data. Moreover, the elicited responses correlated very well with 
the increases (VIP) and decreases (NPY, SOM) in cerebral blood flow observed after intravenous or intracerebral injection of these peptides (Yaksh et al., 1987; Tuor et al., 1990; Long et al., 1992). Particularly, mRNAs for VPAC1 receptors that are reputed to mediate dilatation in pial arteries (Yaksh et al., 1987; Fahrenkrug et al., 2000), were expressed in smooth muscle cells of intracortical microvessels, and VIP elicited a potent dilatation in these microvessels. In contrast, the failure of CCK to alter microvascular tone correlated well with the lack of CCK receptor expression in microvascular smooth muscle, suggesting that this peptide is unlikely to directly couple flow to neuronal activity. We found that NPY induced contraction of intracortical microvessels consistent with contractile NPY-Y1 receptor mRNAs (Abounader et al., 1999) and proteins (Bao et al., 1997) in cortical microarterioles. Intracortical microvessels were also highly responsive to the NO donor DEA NONOate, further emphasizing the opposite vasomotor role of colocalized NO and NPY ( \pm SOM) within cortical interneurons. Likewise, astrocytes expressed various receptors for the neuropeptides found in perivascular GABA interneurons (Martin et al., 1992; Viollet et al., 1997; Abounader et al., 1999). Although they may possibly participate in the interneuron-driven vascular responses, no information is yet available on the release of vasoactive substances from astrocytes activated by VIP, NPY, or SOM. Moreover, release of such molecules from perivascular astrocytes, akin to the dilatory role of GABA on microvessels (Fergus and Lee, 1997), would offer no selectivity in vasomotor responses in contrast to neuropeptides acting on subtype-specific receptors to distinctly alter microvascular tone.

\section{Afferent inputs to different subsets of GABA neurons and functional implications}

Although comparable proportions of interneurons were targeted by 5 -HT afferents $(\sim 40 \%)$, the ACh input varied greatly depending on cell type, and $\sim 45-60 \%$ of it originated in the basal forebrain, implying that intracortical input from ACh interneurons cannot be overlooked (Eckenstein and Baughman, 1984; Chédotal et al., 1994a). NOS neurons were the most frequently contacted by ACh afferents ( 70\%), followed by SOM (57\%), VIP/ ChAT (35-40\%), small NPY neurons not colocalized with NOS (30\%), and, finally, VIP cells not colocalized with ChAT (2026\%). Consistent with ACh and 5-HT innervations of the cerebral cortex acting mainly through diffuse transmission (Descarries and Mechawar, 2000), the ACh input to NOS neurons has previously been found to be mainly nonjunctional (Vaucher et al., 1997). A larger proportion $(\sim 30 \%)$ of NOS neurons also received both ACh and 5-HT innervations compared with other interneurons (10-19\%). NOS neurons thus appear exceptionally well positioned to relay ACh and 5-HT afferent information to blood vessels as they also exquisitely contact neighboring and remotely located blood vessels (Fig. 6B,C) (Estrada and DeFelipe, 1998). The findings that subcortical vasoactive ACh and 5-HT pathways target, albeit to different extent, cortical interneurons able to alter microvascular tone, imply that interneurons act as local relays in regulating cerebral blood flow. Such conclusion is in keeping with the observed attenuation in the cortical vasodilatation elicited from subcortical pathways after selective lesion of cortical neurons (Iadecola et al., 1987).

It is noteworthy that VIP interneurons are activated by muscarinic receptors (Kawaguchi, 1997) and selectively depolarized by nicotinic and $5-\mathrm{HT}_{3}$ ionotropic receptors (Porter et al., 1999; Ferezou et al., 2002). The later may enable VIP cells to rapidly integrate modulatory ACh and 5-HT incoming signals and cou- ple perfusion to changes in local neuronal activity. Additionally, basal forebrain-induced increase in cortical blood flow is not only sensitive to muscarinic and nicotinic blockade but also to NO synthase inhibition (for review, see Hamel, 2004). NOS interneurons, via muscarinic activation (Moro et al., 1995), may modulate perivascular release of $\mathrm{NO}$, which then either directly dilates microvessels or assists in the relaxing effect of ACh on cortical microarterioles (Elhusseiny and Hamel, 2000; Hamel, 2004). Similarly, the changes in cortical perfusion elicited by dorsal raphe stimulation could involve 5-HT3 receptor-mediated activation of VIP interneurons (Ferezou et al., 2002) as well as other serotonin-responsive interneurons (Foehring et al., 2002) equally contacted by 5-HT terminals (Paspalas and Papadopoulos, 2001; our study). Yet, other pathways could use interneurons as relays. Indeed, during increased cortical activity associated with sensory stimulations or local neuronal processing, glutamate release induces the synthesis of vasodilatory mediators (for review, see Iadecola, 2004) by interneurons and/or perivascular astrocytes, which express metabotropic and ionotropic glutamate receptors, thereby participating in the associated raise in local perfusion.

We conclude that subsets of GABA interneurons are strategically positioned to transmute incoming neuronal afferent signals into vascular responses. Specifically, we suggest that subcortical vasoactive systems, as demonstrated here with the basal forebrain $\mathrm{ACh}$ and brainstem 5-HT pathways, in addition to their direct projections and vasomotor effects on cortical microvessels, can use cortical GABA interneurons as relays and local integrators of neurovascular coupling (Fig. 7).

\section{References}

Abounader R, Hamel E (1997) Associations between Neuropeptide Y nerve terminals and intraparenchymal microvessels in rat and human cerebral cortex. J Comp Neurol 388:444-453.

Abounader R, Elhusseiny A, Cohen Z, Olivier A, Stanimirovic D, Quirion R, Hamel E (1999) Expression of neuropeptide Y receptors mRNA and protein in human brain vessels and cerebromicrovascular cells in culture. J Cereb Blood Flow Metab 19:155-163.

Bao L, Kopp J, Zhang X, Xu Z-QD, Zhang L-F, Wong H, Walsh J, Hokfelt T (1997) Localization of neuropeptide Y Y1 receptors in cerebral blood vessels. Proc Natl Acad Sci USA 94:12661-12666.

Bayraktar T, Staiger JF, Acsady L, Cozzari C, Freund TF, Zilles K (1997) Co-localization of vasoactive intestinal polypeptide, gammaaminobutyric acid and choline acetyltransferase in neocortical interneurons of the adult rat. Brain Res 757:209-217.

Cauli B, Audinat E, Lambolez B, Angulo MC, Ropert N, Tsuzuki K, Hestrin S, Rossier J (1997) Molecular and physiological diversity of cortical nonpyramidal cells. J Neurosci 17:3894-3906.

Cauli B, Porter JT, Tsuzuki K, Lambolez B, Rossier J, Quenet B, Audinat E (2000) Classification of fusiform neocortical interneurons based on unsupervised clustering. Proc Natl Acad Sci USA 97:6144-6149.

Chédotal A, Cozzari C, Faure MP, Hartman BK, Hamel E (1994a) Distinct choline acetyltransferase (ChAT) and vasoactive intestinal polypeptide (VIP) bipolar neurons project to local blood vessels in the rat cerebral cortex. Brain Res 646:181-193.

Chédotal A, Umbriaco D, Descarries L, Hartman BK, Hamel E (1994b) Neurovascular relationships of cholinergic and VIPergic nerve terminals in rat cerebral cortex. J Comp Neurol 343:57-71.

Cohen Z, Bonvento G, Lacombe P, Hamel E (1996) Serotonin in the regulation of brain microcirculation. Prog Neurobiol 50:335-362.

Curtis SB, Hewitt J, Yakubovitz S, Anzarut A, Hsiang YN, Buchan AM (2000) Somatostatin receptor subtype expression and function in human vascular tissue. Am J Physiol Heart Circ Physiol 278:H1815-H1822.

Descarries L, Mechawar N (2000) Ultrastructural evidence for diffuse transmission by monoamine and acetylcholine neurons of the central system. Prog Brain Res 125:27-47.

Dutour A, Kumar U, Panetta R, Ouafik L, Fina F, Sasi R (1998) Expression of somatostatin receptor subtypes in human brain tumors. Int J Cancer $76: 620-627$. 
Eckenstein F, Baughman RW (1984) Two types of cholinergic innervation in cortex, one co-localized with vasoactive intestinal polypeptide. Nature 309:153-155.

Elhusseiny A, Hamel E (2000) Muscarinic-but not nicotinic-acetylcholine receptors mediate a nitric oxide-dependent dilation in brain cortical arterioles. J Cereb Blood Flow Metab 20:298-305.

Estrada C, DeFelipe J (1998) Nitric oxide-producing neurons in the neocortex: morphological and functional relationship with intraparenchymal microvasculature. Cereb Cortex 8:193-203.

Fahrenkrug J, Hannibal J, Tams J, Georg B (2000) Immunohistochemical localization of the $\mathrm{VIP}_{1}$ receptor $\left(\mathrm{VPAC}_{1} \mathrm{R}\right)$ in rat cerebral blood vessels: relation to PACAP and VIP containing nerves. J Cereb Blood Flow Metab 20:1205-1214.

Ferezou I, Cauli B, Hill EL, Rossier J, Hamel E, Lambolez B (2002) 5-HT3 receptors mediate serotonergic fast synaptic excitation of neocortical vasoactive intestinal peptide/cholecystokinin interneurons. J Neurosci 22:7389-7397.

Fergus A, Lee KS (1997) GABAergic regulation of cerebral microvascular tone in the rat. J Cereb Blood Flow Metab 17:992-1003.

Fergus A, Jin Y, Thai Q-A, Kassell NF, Lee KS (1996) Tonic protein kinase C-mediated vasoconstriction is unmasked when nitric oxide synthase is inhibited in cerebral microvessels. Neuroscience 74:927-934.

Foehring RC, van Brederode JFM, Kinney GA, Spain WJ (2002) Serotonergic modulation of supragranular neurons in rat sensorimotor cortex. J Neurosci 22:8238-8250.

Hamel E (2004) Cholinergic modulation of the cortical microvascular bed. Prog Brain Res 145:171-178.

Harder DR, Zhang C, Gebremedhin D (2002) Astrocytes function in matching blood flow to metabolic activity. News Physiol Sci 16:27-31.

Harrison RV, Harel N, Panesar J, Mount RJ (2002) Blood capillary distribution correlates with hemodynamic-based functional imaging in cerebral cortex. Cereb Cortex 12:225-233.

Iadecola C (2002) Intrinisc signals and functional brain mapping: caution, blood vessels at work. Cereb Cortex 12:223-224.

Iadecola C (2004) Neurovascular regulation in the normal brain and in Alzheimer's disease. Nat Rev 5:347-360.

Iadecola C, Arneric SP, Baker HD, Tucker LW, Reis DJ (1987) Role of local neurons in cerebrocortical vasodilation elicited from cerebellum. Am J Physiol 252:R1082-R1091.

Iadecola C, Beitz AJ, Renno W, Xu XMB, Zhang F (1993) Nitric oxide synthase-containing neural processes on large cerebral arteries and cerebral microvessels. Brain Res 606:148-155.

Kawaguchi Y (1997) Selective cholinergic modulation of cortical GABAergic cell subtypes. J Neurophysiol 78:1743-1747.

Kawaguchi Y, Kubota Y (1997) GABAergic cell subtypes and their synaptic connections in rat frontal cortex. Cereb Cortex 7:476-486.

Krimer LS, Muly III EC, Williams GV, Goldman-Rakic PS (1998) Dopaminergic regulation of cerebral cortical microcirculation. Nat Neurosci $1: 286-289$.

Kubota Y, Hattori R, Yui Y (1994) Three distinct subpopulations of GABAergic neurons in rat frontal agranular cortex. Brain Res 649:159-173.

Lambolez B, Audinat E, Bochet P, Crépel F, Rossier J (1992) AMPA receptor subunits expressed by single Purkinje cells. Neuron 9:247-258.

Lauritzen M, Gold L (2003) Brain function and neurophysiological correlates of signals used in functional neuroimaging. J Neurosci 23:3972-3980.

Lindauer U, Megow K, Matsuda H, Dirnagl U (1999) Nitric oxide: a modulator, but not a mediator, of neurovascular coupling in rat somatosensory cortex. Am J Physiol 277:H799-H811.

Logothetis NK, Pauls J, Augath M, Trinath T, Oeltermann A (2001) Neuro- physiological investigation of the basis of the fMRI signal. Nature 412:150-157.

Long JB, Rigamonti DD, Dosaka K, Kraimer JM, Martinez-Arizala A (1992) Somatostatin causes vasoconstriction, reduces blood flow and increases vascular permeability in the rat central nervous system. J Pharmacol Exp Ther 260:1425-1432.

Martin J-L, Feinstein DL, Yu N, Sorg O, Rossier C, Magistretti PJ (1992) VIP receptor subtypes in mouse cerebral cortex: evidence for a differential localization in astrocytes, microvessels and synaptosomal membranes. Brain Res 587:1-12.

Moro V, Badaut J, Springhetti V, Edvinsson L, Seylaz J, Lasbennes F (1995) Regional study of the co-localization of neuronal nitric oxide synthase with muscarinic receptors in the rat cerebral cortex. Neuroscience 69:797-805.

Nakai K, Naka Y, Yokote H, Ikatura T, Imai H, Komai N, Maeda T (1989) Vascular "sphincter" and microangioarchitecture in the central nervous system: constriction of intraparenchymal blood vessels following a treatment of vasoconstrictive neurotransmitter. Scanning Microsc 3:337-341.

Paspalas CD, Papadopoulos GC (1998) Ultrastructural evidence for combined action of noradrenaline and vasoactive intestinal polypeptide upon neurons, astrocytes, and blood vessels of the rat cerebral cortex. Brain Res Bull 45:247-259.

Paspalas CD, Papadopoulos GC (2001) Serotoninergic afferents preferentially innervate distinct subclasses of peptidergic interneurons in the rat visual cortex. Brain Res 891:158-167.

Porter JT, Cauli B, Tsuzuki K, Lambolez B, Rossier J, Audinat E (1999) Selective excitation of subtypes of neocortical interneurons by nicotinic receptors. J Neurosci 19:5228-5235.

Raichle ME (1998) Behind the scenes of functional brain imaging: a historical and physiological perspective. Proc Natl Acad Sci USA 95:765-772.

Sagher O, Zhang X-Q, Szeto W, Thai QA, Jin Y, Kassell NF, Lee KS (1993) Live computerized videomicroscopy of cerebral microvessels in brain slices. J Cereb Blood Flow Metab 13:676-682.

Tong XK, Hamel E (2000) Basal forebrain nitric oxide synthase (NOS)containing neurons project to microvessels and NOS neurons in the rat neocortex: cellular basis for cortical blood flow regulation. Eur J Neurosci 12:2769-2780.

Tuor UI, Kelly PAT, Edvinsson L, McCulloch J (1990) Neuropeptide Y and the cerebral circulation. J Cereb Blood Flow Metab 10:591-601.

Vaucher E, Linville D, Hamel E (1997) Cholinergic basal forebrain projections to nitric oxide synthase-containing neurons in the rat cerebral cortex. Neuroscience 79:827-836.

Vaucher E, Tong X-K, Cholet N, Lantin S, Hamel E (2000) GABA neurons provide a rich input to microvessels but not nitric oxide neurons in the rat cerebral cortex: a means for direct regulation of local cerebral blood flow. J Comp Neurol 421:161-171.

Viollet C, Lanneau C, Faivre-Bauman A, Zhang J, Djordjijevic D, Loudes C, Gardette R, Kordon C, Epelbaum J (1997) Distinct patterns of expression and physiological effects of sst 1 and sst 2 receptor subtypes in mouse hypothalamic neurons and astrocytes in culture. J Neurochem 68:2273-2280.

Woolsey TA, Rovainen CM, Cox SB, Henegar MH, Liang GE, Liu D, Moskalenko YE, Sui J, Wei L (1996) Neuronal units linked to microvascular modules in cerebral cortex: response elements for imaging the brain. Cereb Cortex 6:647-660.

Yaksh TL, Wang J-Y, Go VLW (1987) Cortical vasodilatation produced by vasoactive intestinal polypeptide (VIP) and by physiological stimuli in the cat. J Cereb Blood Flow Metab 7:315-326.

Zonta M, Angulo MC, Gobbo S, Rosengarten B, Hossmann K-A, Pozzan T, Carmignoto G (2003) Neuron-to-astrocyte signaling is central to the dynamic control of brain microcirculation. Nat Neurosci 6:43-50. 